\title{
Impacts of restricted feeding and realimentation on bone development and plasma concentrations of bone-specific biomarkers in lambs
}

\author{
A.A. Swelum ${ }^{1,3,5,6}$, I.M. Saadeldin ${ }^{1,4,6}$, A.N. Alowaimer ${ }^{1}$, A. Mahmoud ${ }^{2}$ and M.A. Abouheif ${ }^{1}$ \\ King Saud University \\ ${ }^{1}$ College of Food and Agriculture Sciences, Department of Animal Production \\ ${ }^{2}$ College of Science, Department of Zoology, Riyadh 11451, Saudi Arabia \\ Zagazig University, Faculty of Veterinary Medicine \\ ${ }^{3}$ Department of Theriogenology, ${ }^{4}$ Department of Physiology, Zagazig 44519, Egypt
}

KEY WORDS: feed restriction, bone length, phosphorus, osteocalcin, lambs

Received: 15 July 2014

Revised: 11 January 2017

Accepted: 1 June 2017

${ }^{5}$ Corresponding author:

e-mail: aswelum@ksu.edu.sa

${ }^{6}$ These authors contributed equally to this work
ABSTRACT. The aim of the study was to assess the effect of feed restriction levels followed by realimentation on long bone growth and concentrations of growth hormone, osteocalcin, bone-specific alkaline phosphatase (ALP), calcium $(\mathrm{Ca})$ and phosphorus $(\mathrm{P})$ in plasma. Thirty-six Najdi ram lambs weighing $30.1 \pm 0.3 \mathrm{~kg}$ were randomly allotted to one of three feeding regimens. The first group was fed ad libitum throughout the trial (AD group). Other groups were subjected to 5 -week feed restriction at either 0.75 or 0.60 of ad libitum intake (0.75AD and 0.60AD groups, respectively). Following the restriction period, lambs were returned to ad libitum feeding (realimentation) for 7 weeks. Feed restriction suppressed $(P<0.01)$ the growth of bone lengths in proportion to the restriction level. After the realimentation, bone lengths of animals from either $0.75 \mathrm{AD}$ or $0.60 \mathrm{AD}$ groups did not recover to the lengths of $A D$ group. Plasma concentrations of inorganic $P$ and osteocalcin decreased $(P<0.01)$ as the level of feed restriction increased. Concentration of plasma bone-specific ALP increased $(P<0.01)$ by 39.6 and $72.7 \%$ in $0.75 \mathrm{AD}$ and $0.60 \mathrm{AD}$ groups, respectively. After 4 weeks of realimentation, plasma concentrations of osteocalcin, ALP and P did not differ between all groups. The ulna, humerus and femur linear lengths were directly correlated with the level of osteocalcin and P; however, they showed a negative correlation with the level of ALP. Therefore, plasma concentration of $\mathrm{P}$, osteocalcin and ALP appeared to be suitable bone markers for detecting changes in bone length due to variation in feed restriction levels.

\section{Introduction}

Livestock enterprises in Saudi Arabia are likely to depend almost entirely on imported feed ingredients. To mitigate the increasing costs of feeds and to make lamb production profitable, efforts have started to create possible strategies to reduce the costs of production through the phases of feed restriction and realimentation without compromising future growth performance. Several studies have reported the impact of different levels of feed restriction on body weight (Abouheif et al., 2013; Sami et al., 2013), but attention has hardly been paid to bone growth, despite the intimate association of 
these tissues in young lambs; muscle is supported by the skeleton and grows in response to passive stretch (Peralta et al., 1994). However, the response of bone growth varies according to the pattern of restriction, realimentation and stage of lamb development (Nicodemo et al., 1999; Prentice et al., 2006; Remmers et al., 2008). Dashtizadeh et al. (2008) reported that feed restriction resulted in retarded bone growth of different body parts in young animals depending on their maturity.

Many bone-specific biochemical markers have been identified and can be used as potential indicators of bone cell formation and turnover (Scott et al., 1997). Those used to monitor the bone formation are products of the osteoblast, including osteocalcin and bone-specific alkaline phosphatase (ALP), and were reported to reflect the activity of these cells in bone (Nicodemo et al., 1999). Feed intake was an important determinant of blood osteocalcin concentration and bone formation (Ndiaye et al., 1992; Scott et al., 1997). Prentice et al. (2006) reported that serum concentration of osteocalcin was low in children suffering from protein-energy malnutrition and increased significantly during nutritional recovery. As part of our studies on the effects of feed restriction on lamb performance, the applicability of different biomarkers of bone turnover to detect changes in bone growth caused by various levels of feed restriction would be of considerable value in physiological and nutritional studies. Thus, the present study was carried out to examine the effects of short-term feed restrictions (two levels) on long bone growth and plasma concentrations of $\mathrm{Ca}, \mathrm{P}$, growth hormone $(\mathrm{GH})$, bone-specific ALP and osteocalcin in growing Najdi lambs.

\section{Material and methods}

\section{Animals and housing}

Thirty-six Najdi ram lambs of an average body weight $30.1 \pm 0.3 \mathrm{~kg}$ ( $40 \%$ of mature weight) and about $110 \pm 3$ days old, were randomly assigned to one of three groups (12 lambs/group). Lambs were vaccinated against endemic infectious diseases, treated with a prophylactic dose of Ivermectin (Ivomec Injection, Merial Australia Pty Ltd., Macquarie Park, Australia) with the addition of vitamins A, $\mathrm{D}_{3}$ and E (IU: 150 000, 37500 and 150, respectively). All lambs were kept under similar environmental and management conditions ( 4 replicates/pens with 3 lambs per pen). Pens $(1.7 \times 3.0 \mathrm{~m})$ constructed of metal gates and concrete floors were placed under a roof in an open-sided barn.

\section{Feeding protocol}

The experimental groups were randomly allotted to one of three feeding regimens: the first group was fed ad libitum throughout the trial (AD group), the second and third group were subjected to 5 weeks of feed restriction at either 0.75 (0.75 AD group) or 0.60 (0.60AD group) of ad libitum intake, respectively. Following the restriction period, lambs were returned to ad libitum feeding (realimentation period) for 7 weeks. Feeding levels of restricted groups were calculated by determining the average dry matter (DM) intake of lambs with ad libitum access to feed the previous week and multiplying that average by 0.75 and 0.60 to determine the amount of feed intake per $\mathrm{kg}$ live weight offered to lambs from $0.75 \mathrm{AD}$ and $0.60 \mathrm{AD}$ groups, respectively. During the experimental period (12 weeks), DM consumption was recorded every week.

All lambs were fed commercial pellets at 09:00 $\mathrm{h}$ after discarding the refusals from the previous day. Refusals were weighed, sampled for DM determination and then discarded. The commercial pellets were formed as a pelleted totalmixed ration with a ratio of $75 \%$ concentrate: $25 \%$ lucerne hay; the chemical composition (DM basis) was, \%: 14.53 crude protein (CP), 1.16 ether extract (EE), 24.91 neutral detergent fibre (NDF), 14.22 acid detergent fibre (ADF), $0.54 \mathrm{Ca}, 0.31 \mathrm{P}$, 7.46 ash and the metabolizable energy (ME) was $2.78 \mathrm{Mcal} \cdot \mathrm{kg}^{-1} \mathrm{DM}$. The trace-minerals mixture blocks were placed in all pens. Fresh drinking water was freely available.

\section{Bone measurements}

In live lambs, the lengths of right forelimb and hindlimb bones were recorded at the onset of restriction period, at the end of restriction period and at the end of the experiment by the same person throughout the trial and measured with an accuracy of $0.1 \mathrm{~cm}$ using vernier caliper. The measured bones were:

- humerus: the distance between the eminent part of shoulder joint and the elbow joint,

- ulna: the distance between the elbow joint and distal end of the carpal joint,

- metacarpus: the distance between the carpal joint and fetlock joint,

- femur: the distance between the eminent part of the hip joint and the stifle joint,

- tibia: the distance between the stifle joint and the distal end of the tarsal joint,

- metatarsus: the distance between the tarsal joint and fetlock joint. 


\section{Plasma biochemistry}

At the end of restriction period and after 4-week realimentation, whole blood samples $(10 \mathrm{ml})$ from the jugular vein of each lamb were collected into heparinized tubes. Plasma was separated by centrifugation at $1000 \mathrm{~g}$ for $10 \mathrm{~min}$ in a refrigerated centrifuge, immediately apportioned into three $0.5 \mathrm{ml}$ aliquots and stored frozen in polypropylene tubes at $-20{ }^{\circ} \mathrm{C}$ until further analysis. Plasma concentration of $\mathrm{Ca}$ was measured by atomic-absorption spectroscopy (Spectra AA-200 Varian, Varian Techtron Pty. Limited, Victoria, Australia) while plasma concentration of $\mathrm{P}$ was measured photometrically at $340 \mathrm{~nm}$ (Cobas Mira, Roche Diagnostics Systems, Basel, Switzerland) using a Roche Diagnostics kit (Roche Diagnostics GmbH, Annheim, Germany). Plasma GH concentration was measured as described by MacRae et al. (1991) while bone-specific alkaline phosphatase level was measured by immunoassay (Alkphase-B kit, Metra Biosystem, CA, USA). Plasma osteocalcin concentration was measured using an enzyme-linked immunoabsorbent assay test (ELISA) according to procedures described by Peterson et al. (2005).

Table 1. Average daily gain and daily intake of dry matter (DMI), Ca and P during 5 weeks of feed restriction and 7 weeks of realimentation

\begin{tabular}{|c|c|c|c|c|c|c|c|c|}
\hline \multirow{2}{*}{ Indices } & \multicolumn{4}{|c|}{ Restriction period } & \multicolumn{4}{|c|}{ Realimentation period } \\
\hline & $\overline{A D^{1}}$ & $0.75 A^{2}$ & $0.60 \mathrm{AD}^{3}$ & SEM & $A D$ & $0.75 \mathrm{AD}$ & $0.60 \mathrm{AD}$ & SEM \\
\hline $\mathrm{DMl}, \mathrm{g} \cdot \mathrm{kg} \mathrm{BW} \mathrm{W}^{-1} \cdot \mathrm{d}^{-1}$ & $43.1^{\mathrm{a}}$ & $32.8^{\mathrm{b}}$ & $25.9^{c}$ & 3.1 & 38.9 & 42.3 & 42.7 & 2.1 \\
\hline Average daily gain, $\mathrm{g}$ & $275^{a}$ & $143^{b}$ & $82^{c}$ & 110 & 306 & 315 & 325 & 21 \\
\hline Ca intake, $\mathrm{mg} \cdot \mathrm{kg} \mathrm{BW}^{-1} \cdot \mathrm{d}^{-1}$ & $233^{a}$ & $177^{\mathrm{b}}$ & $140^{\circ}$ & 18.6 & 210 & 228 & 231 & 9.5 \\
\hline$P$ intake, $\mathrm{mg} \cdot \mathrm{kg} \mathrm{BW}^{-1} \cdot \mathrm{d}^{-1}$ & $134^{a}$ & $102^{b}$ & $80^{c}$ & 11.0 & 121 & 131 & 132 & 4.7 \\
\hline
\end{tabular}

1 - group with ad libitum feed intake; ${ }^{2}$ - group with 0.75 restriction of ad libitum feed intake; ${ }^{3}$ - group with 0.60 restriction of ad libitum feed intake; SEM - standard error of the mean; BW - body weight; abc - means with different superscripts within the same row within each period are significantly different at $P<0.01$

Table 2. Bone lengths in growing lambs after 5 weeks of feed restriction and 7 weeks of realimentation

\begin{tabular}{|c|c|c|c|c|c|c|c|c|}
\hline \multirow{2}{*}{ Indices } & \multicolumn{4}{|c|}{ Forelimb } & \multicolumn{4}{|c|}{ Hindlimb } \\
\hline & $\overline{A D^{1}}$ & $0.75 A D^{2}$ & $0.60 \mathrm{AD}^{3}$ & SEM & $\overline{A D}$ & $0.75 \mathrm{AD}$ & $0.60 \mathrm{AD}$ & SEM \\
\hline & \multicolumn{4}{|c|}{ Metacarpus, cm } & \multicolumn{4}{|c|}{ Metatarsus, $\mathrm{cm}$} \\
\hline Start of restriction & 18.00 & 17.90 & 18.10 & 0.09 & 23.20 & 23.20 & 23.10 & 0.12 \\
\hline End of restriction & 19.40 & 19.10 & 19.40 & 0.11 & 23.60 & 23.60 & 23.50 & 0.14 \\
\hline \multirow[t]{2}{*}{ End of experiment } & 22.20 & 22.20 & 22.50 & 0.13 & 25.60 & 25.65 & 25.40 & 0.13 \\
\hline & \multicolumn{4}{|c|}{ Ulna, cm } & \multicolumn{4}{|c|}{ Tibia, cm } \\
\hline Start of restriction & 22.40 & 22.50 & 22.45 & 0.13 & 26.60 & 26.60 & 26.50 & 0.12 \\
\hline End of restriction & $24.40^{\mathrm{a}}$ & $24.00^{b}$ & $23.40^{c}$ & 0.13 & $32.20^{a}$ & $31.60^{\mathrm{b}}$ & $31.60^{b}$ & 0.13 \\
\hline \multirow[t]{2}{*}{ End of experiment } & $25.80^{\mathrm{a}}$ & $25.20^{b}$ & $24.75^{c}$ & 0.14 & $34.40^{\mathrm{a}}$ & $34.00^{\mathrm{ab}}$ & $33.90^{b}$ & 0.14 \\
\hline & \multicolumn{4}{|c|}{ Humerus, cm } & \multicolumn{4}{|c|}{ Femur, cm } \\
\hline Start of restriction & 18.60 & 19.00 & 18.70 & 0.09 & 21.40 & 21.25 & 21.30 & 0.14 \\
\hline End of restriction & $22.20^{\mathrm{a}}$ & $21.60^{b}$ & $21.20^{c}$ & 0.09 & $29.00^{\mathrm{a}}$ & $28.40^{\mathrm{b}}$ & $28.00^{c}$ & 0.15 \\
\hline End of experiment & $24.60^{a}$ & $23.60^{b}$ & $23.00^{b}$ & 0.15 & $31.80^{a}$ & $29.75^{b}$ & $29.70^{b}$ & 0.14 \\
\hline
\end{tabular}

${ }_{1,2,3}$ see Table 1; SEM - standard error of the mean; abc - means with different superscripts within the same row within each limb are significantly different at $P<0.01$

Table 3. Plasma concentration of some bone markers in growing lambs after 5 weeks of feed restriction and after 4 weeks of realimentation

\begin{tabular}{|c|c|c|c|c|c|c|c|c|}
\hline \multirow{2}{*}{ Plasma concentration } & \multicolumn{4}{|c|}{ Restriction period } & \multicolumn{4}{|c|}{ Realimentation period } \\
\hline & $\overline{\mathrm{AD}^{1}}$ & $0.75 \mathrm{AD}^{2}$ & $0.60 \mathrm{AD}^{3}$ & SEM & $\overline{A D}$ & $0.75 \mathrm{AD}$ & $0.60 \mathrm{AD}$ & SEM \\
\hline Growth hormone, $\mathrm{ng} \cdot \mathrm{ml}^{-1}$ & 8.1 & 7.5 & 7.9 & 2.4 & 9.8 & 9.3 & 10.1 & 2.1 \\
\hline Osteocalcin, $\mathrm{ng} \cdot \mathrm{ml}^{-1}$ & $286^{a}$ & $265^{\mathrm{ab}}$ & $250^{b}$ & 14.2 & 265 & 257 & 247 & 13.0 \\
\hline Alkaline phosphatase, $U \cdot I^{-1}$ & $139^{c}$ & $194^{b}$ & $240^{a}$ & 18.3 & 134 & 126 & 119 & 10.3 \\
\hline $\mathrm{Ca}, \mathrm{mg} \cdot \mathrm{dl}^{-1}$ & 8.4 & 8.4 & 8.1 & 0.12 & 8.4 & 7.6 & 8.5 & 0.08 \\
\hline$\underline{\mathrm{P}, \mathrm{mg} \cdot \mathrm{dl}^{-1}}$ & $5.1^{\mathrm{a}}$ & $4.8^{\mathrm{ab}}$ & $4.4^{\mathrm{b}}$ & 0.15 & 4.9 & 5.0 & 4.9 & 0.06 \\
\hline
\end{tabular}

$1,2,3$ see Table 1; SEM - standard error of the mean; abc - means with different superscripts withinin the same row within each period are significantly different at $P<0.01$ 


\section{Statistical analysis}

Data for DM intakes, bone lengths and plasma concentrations of bone biomarkers during all periods of the experiment were estimated by analysis of variance (ANOVA) using GLM procedures (SAS, 2002). Duncan's multiple range test was used to test for significant differences between means. Regression analysis between the blood parameters and linear body growth, including correlation coefficient, intercept and regression coefficient were also analysed using SAS.

\section{Results}

All lambs maintained good health throughout the study. The intakes of DM, Ca and P decreased $(P<0.01)$ as the level of the applied feed restriction increased (Table 1). Average daily gain (ADG) increased during the restriction phase $(P<0.01)$ as the level of feed restriction was decreased; in comparison with $\mathrm{AD}$ group, the growth rates decreased by 48 and $70 \%$ in $0.75 \mathrm{AD}$ and 0.60AD groups, respectively. On the other hand, daily $\mathrm{DM}, \mathrm{Ca}$ and $\mathrm{P}$ intakes during the realimentation period of both restriction levels were similar $(P>0.01)$ as compared with lambs from $\mathrm{AD}$ group.
At the onset of restriction period, differences between the studied long bone lengths of different feed restriction groups were non-significant (Table 2). Except for the metacarpus and metatarsus bone lengths, feed restriction significantly suppressed $(P<0.01)$ the length of other studied long bone lengths. After the realimentation, bones lengths did not recover to the lengths of bones occurring in $\mathrm{AD}$ group, except the length of tibia in $0.75 \mathrm{AD}$ group.

Plasma concentrations of growth hormone and $\mathrm{Ca}$ in lambs from $0.75 \mathrm{AD}$ and $0.60 \mathrm{AD}$ groups did not differ $(P>0.01)$ at the end of restriction period (Table 3). On the other hand, plasma concentrations of $\mathrm{P}$ and osteocalcin decreased $(P<0.01)$ as the level of feed restriction increased; however, the level of ALP showed significant increase alongside as the level of the applied feed restriction increased. The plasma concentration of osteocalcin, bone specific ALP, Ca and $\mathrm{P}$ after 4 weeks of realimentation did not differ $(P>0.01)$ between feed-restricted groups and $\mathrm{AD}$ group.

The ulna, humerus and femur linear lengths were directly correlated with the level of osteocalcin and $P$ however, they showed a negative correlation with the level of ALP $(P<0.01$; Table 4 and Figures $1-3)$. Tibia linear length showed no significant correlation with the studied blood parameters $(P>0.05)$.

Table 4. Analysis of correlation coefficient and regression coefficient among serum phosphorous content $(\mathrm{P})$, serum alkaline phosphatase level (ALP) and serum osteocalcin concentration with different bones lengths

\begin{tabular}{|c|c|c|c|c|c|c|c|c|c|c|c|c|}
\hline & \multicolumn{12}{|c|}{ Bone length } \\
\hline & \multicolumn{3}{|l|}{ ulna } & \multicolumn{3}{|l|}{ humerus } & \multicolumn{3}{|l|}{ tibia } & \multicolumn{3}{|l|}{ femur } \\
\hline & correlation & regression & $P$-value & correlation & regression & $P$-value & correlation & regression & $P$-value & correlation & regression & $P$-value \\
\hline $\bar{P}$ & 0.66 & 0.032479 & 0.00 & 0.46 & 0.00903 & 0.00 & 0.23 & 0.010706 & 0.19 & 0.57 & 0.011421 & 0.00 \\
\hline ALP & -0.66 & -3.12522 & 0.00 & -0.71 & -3.38385 & 0.00 & -0.26 & -1.34154 & 0.14 & -0.63 & -0.55071 & 0.00 \\
\hline Osteocalcin & 0.44 & 0.699328 & 0.00 & 0.48 & 0.831682 & 0.00 & 0.26 & 0.548312 & 0.14 & 0.57 & 0.743245 & 0.00 \\
\hline
\end{tabular}



Figure 1. Linear lengths $(\mathrm{mm})$ of ulna, humerus, tibia and femur in relation with serum osteocalcin level $\left(\mathrm{ng} \cdot \mathrm{ml}^{-1}\right)$ 




Figure 2. Linear lengths $(\mathrm{mm})$ of ulna, humerus, tibia and femur in relation with serum alkaline phosphatase (ALP) level $\left(\right.$ unit $\left.\cdot I^{-1}\right)$



Figure 3. Linear lengths $(\mathrm{mm})$ of ulna, humerus, tibia and femur in relation with serum phosphorous level $\left(\mathrm{mg} \cdot \mathrm{dl}^{-1}\right)$

\section{Discussion}

Average daily intake of $\mathrm{Ca}$ in $0.60 \mathrm{AD}$ group during the restriction period $\left(140 \mathrm{mg} \cdot \mathrm{kg}^{-1}\right.$ body weight $(\mathrm{BW})$ ) was adequate and within the normal range listed for growing sheep according to NRC (2007). The daily $\mathrm{P}$ intakes during restriction period were 134, 102 and $80 \mathrm{mg} \cdot \mathrm{kg}^{-1} \mathrm{BW}$ for $\mathrm{AD}$, $0.75 \mathrm{AD}$ and $0.60 \mathrm{AD}$ groups, respectively. Louvandini and Vitti (1996) classified the adequacy of daily-consumed $\mathrm{P}$ in sheep weighing between 38 and $40 \mathrm{~kg}$ as $30-80 \mathrm{mg} \cdot \mathrm{kg}^{-1} \mathrm{BW}$ - marginally deficient; $80-100 \mathrm{mg} \cdot \mathrm{kg}^{-1} \mathrm{BW}$ - adequate; $>100 \mathrm{mg} \cdot \mathrm{kg}^{-1}$ BW - excessive. On the other hand, in the study of Portilho et al. (2006) greater values of P as: $111.1 \mathrm{mg} \cdot \mathrm{kg}^{-1}$ BW was considered deficient; $195.7 \mathrm{mg} \cdot \mathrm{kg}^{-1} \mathrm{BW}$ - moderate and $274.8 \mathrm{mg} \cdot \mathrm{kg}^{-1}$ $\mathrm{BW}$ as adequate for young growing Santa Inês lambs weighing $22 \mathrm{~kg}$. In the present study, the levels of daily $\mathrm{P}$ intake during feed restriction were thought to be marginal.

Except for the metacarpus and metatarsus bone lengths, the long-bone lengths in $0.75 \mathrm{AD}$ lambs were shorter $(P<0.01)$ by $4.07-6.51 \%$ than in AD group, indicating that a low nutrients supply during growth impairs the normal development of long bones in proportion to the restriction plane of nutrition (Nicodemo et al., 1999; Dashtizadeh et al., 2008). At the 
end of the trial, bone lengths of the restrictively fed lambs were shorter $(P<0.01)$ and did not recover to the lengths of $\mathrm{AD}$ lambs. This result was in agreement with the findings of Remmers et al. (2008) who observed that feed restriction in younger animals acutely reduced body dimensions.

Interestingly, the decrease in the linear growth of long bones, except tibia, showed direct correlation $(P<0.01)$ with the reduced levels of osteocalcin (Figure 1) and $\mathrm{P}$ (Figure 3). However, it showed a negative correlation with the increase of alkaline phosphatase level (Figure 2). Specifically, plasma osteocalcin concentration decreased $(P<0.01)$ as the feed restriction level increased. This trend was consistent with the decrease in osteocalcin concentration when feed or P intakes were restricted (Scott et al., 1997; Kang et al., 2010). Reduced plasma concentration of osteocalcin in the feed-restricted lambs might result from decreased activity by osteoblasts (Clemens and Karsenty, 2011). Ndiaye et al. (1992) and Scott et al. (1997) showed that osteocalcin concentration was reduced by energy restriction and these changes resulted mainly from reduction of bone formation. While osteocalcin is the major non-collagenous protein in bone, its function is unknown, although its close association with the mineral matrix had been taken to indicate some role in the mineralization process. Several studies demonstrated that circulating osteocalcin was derived from the new synthesis rather than from the degradation of bone; thus, it provides a measure of osteoblast activity (Clemens and Karsenty, 2011). In this study, the plasma osteocalcin concentrations after 4 weeks of realimentation did not differ $(P>0.01)$ between feed-restricted groups and AD group. This result, however, suggested that the osteoblast cell numbers in feed-restricted groups were probably compensated to attain $\mathrm{AD}$ group during the early stage in realimentation and resulted in similar activity when compared with ad libitum fed lambs. Similar results were reported by Ndiaye et al. (1992) who found that refeeding produced a rapid rise in rat serum osteocalcin, which reached control concentrations after $24 \mathrm{~h}$ of refeeding.

Plasma concentration of bone-specific ALP increased $(P<0.01)$ by 39.6 and $72.7 \%$ when feed intakes were restricted to 0.75 and 0.60 of ad libitum intakes, respectively. ALP is primarily localized in the membrane of osteoblast and its level in the plasma will be related to a combination of the activity of individual osteoblasts and the extent of the bone surface covered by active bone-forming cells. Raised levels of ALP had been reported in a number of metabolic bone disorders especially, in those which a defect in bone matrix mineralization was reported (Belić et al., 2010). In addition, greater plasma ALP concentrations had previously been reported in sheep fed insufficient $P$ diet in comparison with animals receiving adequate $\mathrm{P}$ (Scott et al., 1997).

Plasma concentrations of growth hormone and $\mathrm{Ca}$ for the different levels of feed restriction did not differ $(P>0.01)$ at the end of restriction period. The concentrations of plasma inorganic $P$ were proportionally related to the level of feeding in lambs. Louvandini and Vitti (1996) reported a highly significant positive linear relationship between $\mathrm{P}$ intake and plasma $\mathrm{P}$ concentration in sheep. In this trial, plasma inorganic $\mathrm{P}$ levels varied between 4.4 and $5.1 \mathrm{mg} \cdot \mathrm{dl}^{-1}$, which were within the normal 4-9 $\mathrm{mg} \cdot \mathrm{dl}^{-1}$ range, according to Thompson (1978). It seems that, the $80 \mathrm{mg} \cdot \mathrm{kg} \mathrm{BW}^{-1} \cdot \mathrm{d}^{-1}$ of $\mathrm{P}$ intake in the $0.60 \mathrm{AD}$ lambs was marginal to maintain plasma P level at its 'lower-limit' normal range, but on the other hand, was inadequate to support 'normal' bone growth in young growing Najdi lambs during the restriction period. Prentice et al. (2006) found that maximal bone growth would not occur when the dietary P intake was hardly sufficient to maintain normal plasma P level only.

\section{Conclusions}

Various feed restriction levels in growing lambs resulted in proportional changes in long bone lengths, with ad libitum lambs having longer bones than those of feed-restricted groups. After realimentation, bone length did not recover to the lengths observed in ad libitum fed group. Plasma concentration of phosphorous, osteocalcin and alkaline phosphatase were suitable bone markers for detecting changes in bone length due to variation in feed restriction levels; however, refeeding produced rapid rise in their concentration, which reached the ad libitum level after 4 weeks of realimentation. The ulna, humerus and femur linear lengths were directly correlated with the level of osteocalcin and P however; they showed a negative correlation with the level of alkaline phosphatase. Insufficient energy/nutrient and phosphorus supply must be avoided in the growing animals to ensure high skeleton growth. Further experiments are needed to determine the exact cause of the reduced length of distinct long bones in the restricted group. 


\section{Acknowledgments}

The authors extend their appreciation to the Deanship of Scientific Research at King Saud University for funding this work through research group NO (RG-1438-066).

\section{References}

Abouheif M., Al-Owaimer A., Kraidees M., Metwally H., Shafey T., 2013. Effect of restricted feeding and realimentation on feed performance and carcass characteristics of growing lambs. Rev. Bras. Zootecn. 42, 95-101, http://doi.org/10.1590/S151635982013000200003

Belić M., Svetina A., Kušec V., Rakočević S., Grizelj J., Robić M., Turk R., 2010. Bone alkaline phosphatase, osteocalcin and C-terminal telopeptide as bone turnover markers in canine bitches. Vet. Arh. 80, 705-713

Clemens T.L., Karsenty G., 2011. The osteoblast: an insulin target cell controlling glucose homeostasis. J. Bone Miner. Res. 26, 677680, https://doi.org/10.1002/jbmr.321

Dashtizadeh M., Zamiri M.J., Kamalzadeh A., Kamali A., 2008. Effect of feed restriction on compensatory growth response of young male goats. Iran. J. Vet. Res. 9, 109-120

Kang M.-H., Kim M.-H., Bae Y.-J., Choi M.-K., 2010. Vegetable and fruit intake and its relevance with serum osteocalcin and urinary deoxypyridinoline in Korean adults. Nutr. Res. Pract. 4, 421-427, https://doi.org/10.4162/nrp.2010.4.5.421

Louvandini H., Vitti D.M.S., 1996. Phosphorus metabolism and estimation of phosphorus requirements for sheep. Sci. Agric. 53, 184-189, https://doi.org/10.1590/S0103-90161996000100027

MacRae J.C., Bruce L.A., Hovell F.B.DeB., Hart I.C., Inkster J., Walker A., Atkinson T., 1991. Influence of protein nutrition on the response of growing lambs to exogenous bovine growth hormone. J. Endocrinol. 130, 53-61, https://doi.org/10.1677/joe.0.1300053

Ndiaye B., Prudhon C., Guillozo H., Lemonnier D., 1992. Rat serum osteocalcin concentration is determined by food intake and not by inflammation. J. Nutr. 122, 1870-1874

Nicodemo M.L.F., Scott D., Buchan W., Duncan A., Robins S.P., 1999. Effects of variations in live weight gain on bone growth and composition and on markers of bone turnover in lambs. Exp. Physiol. 84, 579-587, https://doi.org/10.1111/j.1469445X.1999.01825.X
NRC, 2007. Nutrient Requirements of Small Ruminants: Sheep, Goats, Cervids, and New World Camelids. National Academy Press. Washington, DC (USA), https://doi.org/10.17226/11654

Peralta J.M., Arnold A.M., Currie W.B., Thorney M.L., 1994. Effects of testosterone on skeletal growth in lambs as assessed by labeling index of chondrocytes in the metacarpal bone growth plate. J. Anim. Sci. 72, 2629-2634, https://doi. org/10.2527/1994.72102629x

Peterson A.B., Orth M.W., Goff J.P., Beede D.K., 2005. Periparturient responses of multiparous Holstein cows fed different dietary phosphorus concentrations prepartum. J. Dairy Sci. 88, 35823594, https://doi.org/10.3168/jds.S0022-0302(05)73043-5

Portilho F.P., Vitti D.M.S.S., Abdalla A.L., McManus C.M., Rezende M.J.M., Louvandini H., 2006. Minimum phosphorus requirement for Santa Inês lambs reared under tropical conditions. Small Rumin. Res. 63, 170-176, https://doi.org/10.1016/j. smallrumres.2005.03.006

Prentice A., Schoenmakers I., Laskey M.A., de Bono S., Ginty F., Goldberg G.R., 2006. Nutrition and bone growth and development. Proc. Nutr. Soc. 65, 348-360, https://doi.org/10.1079/ PNS2006519

Remmers F., Fodor M., Delemarre-van de Waal H.A., 2008. Neonatal food restriction permanently alters rat body dimensions and energy intake. Physiol. Behav. 95, 208-215, https://doi. org/10.1016/j.physbeh.2008.05.021

Sami A., Shafey T., Abouheif M., 2013. Growth rate of carcass, noncarcass and chemical components of restricted fed and realimented growing lambs. Int. J. Agric. Biol. 15, 307-312

SAS, 2002. SAS User's Guide: Statistics Version. $8^{\text {th }}$ Edition. SAS Inc., Cary, NC (USA)

Scott D., Loveridge N., Nicodemo L., Buchan W., Milne J., Duncan A., Nicol P., Robins S.P., 1997. Effect of diets varying in nitrogen or phosphorus content on indicators of bone growth in lambs. Exp. Physiol. 82, 193-202, https://doi.org/10.1113/expphysiol.1997.sp004008

Thompson W.R., 1978. Phosphorus in Animal Nutrition. Phosphorus for Agriculture: A Situation Analysis. Potash and Phosphate Institute, Atlanta, GA (USA), pp. 126-158 